\title{
Arqueologia Guarani na Bacia do Rio Santo Anastácio, SP: estudo da variabilidade cerâmica do sítio Célia Maria
}

\author{
David Lugli Turtera Pereira $\left({ }^{*}\right)$ \\ Neide Barrocá Faccio ${ }^{* *}$ )
}

\begin{abstract}
PEREIRA, D.L.T.; FACCIO, N.B. A Arqueologia Guarani na Bacia do Rio Santo Anastácio, SP: estudo da variabilidade cerâmica do sítio Célia Maria. R.. Museu Arq. Etn., 24: 77-90.
\end{abstract}

Resumo: A pesquisa realizada na área do sítio arqueológico Célia Maria, localizado na região da Bacia do Rio Santo Anastácio (afluente da Bacia do Paraná), Estado de São Paulo, demonstrou uma ocupação Guarani pré-colonial. A cerâmica foi datada por termoluminescência, situando a ocupação em torno de $450 \pm 60$ anos atrás. Este trabalho traz dados referentes à cerâmica identificada na área do sítio Célia Maria. A partir da análise tecnotipológica da cerâmica, demonstramos a provável sequência dos gestos técnicos para a produção dos artefatos, assim como reconstituímos graficamente a forma de vasos, a partir de fragmentos de bordas. Os dados espaciais dos atributos cerâmicos do sítio Célia Maria foram confrontados com outras pesquisas disponíveis que versaram sobre a presença dos Guarani na Bacia do Paraná e Paranapanema.

Palavras-chave: Arqueologia Guarani; análise cerâmica; Bacia do Rio Santo Anastácio

\section{Introdução}

$\mathrm{O}$ s grupos Guarani parecem ter ocupado massivamente a região da Bacia do Paraná e do Paranapanema, expandindo-se desde os terraços e várzeas próximos aos principais canais fluviais até os tributários mais afastados, já próximos as suas nascentes em um vasto período de 1.668 anos antes do presente até meados do século XX.

$\left({ }^{*}\right)$ Doutorando em Arqueologia, Museu de Arqueologia e Etnologia, Universidade de São Paulo.<davidlugli12@yahoo. com.br>

$\left.{ }^{(* *}\right)$ UNESP, Campus de Presidente Prudente, Laboratório de Arqueologia Guarani. <nfaccio@terra.com.br>
As datações absolutas apontam que as margens do Rio Paraná e Paranapanema Paulista foram mais densamente ocupadas durante uma faixa cronológica de 700 a 1.000 anos antes do presente. Em datas mais recentes, como no caso do sítio Célia Maria, em torno de 500 anos antes do presente pode ter ocorrido um processo de territorialização dos tributários e das nascentes de tributários mais afastados das margens dos grandes rios.

O crescimento contínuo da população nas áreas ecológicas mais favoráveis ao assentamento Guarani devem ter formado uma zona de expulsão/expansão populacional que levou à ocupação de novas áreas mais afastadas e menos propícias a ocupação Guarani. O modelo idealizado por Bro- 
chado e La Salvia (1989) propõe que os grupos Guarani "expandem seu território dividindo as aldeias em células, que se subdividem novamente e assim por diante, de forma a ocupar um espaço territorial a partir de um adensamento populacional" (Milheira 2010: 135).

Nesse hipotético contexto, o sítio arqueológico Célia Maria datado em torno de $450 \pm 60$ anos antes do presente (Faccio 2010) e localizado na Bacia do Rio Santo Anastácio, próximo ao espigão divisor de águas da Bacia do Paraná com a Bacia do Paranapanema, deve representar uma possível expansão territorial Guarani para esta região em tempos mais recentes.

Afastado das margens dos grandes rios e próximo de nascentes de um pequeno córrego, esse ambiente proporcionou recursos suficientes para receber uma pequena comunidade Guarani. O fato materializou-se, nos três núcleos de solos antropogênicos, em alguns milhares de fragmentos cerâmicos com pouca variabilidade de tratamento de superfície, inclusive ausência total do tipo corrugado característico de sítios Guarani do Vale do Rio Paranapanema. O sítio apresentou vasilhas pequenas e médias, com ausência de grandes talhas, para armazenar bebidas, chamadas emicamente por cambuchi. Quanto à indústria lítica, foi encontrado um fragmento de tembetá polido e fragmentos de seixos em quartzo, arenito silicificado, basalto e silexito, sem marcas de ação humana.

\section{Parâmetros locacionais culturalmente rele-} vantes à ocupação pretérita da Bacia do Santo Anastácio

Integrante da Bacia do Rio Paraná, a Bacia Hidrográfica do Rio Santo Anastácio abrange uma área de $2.000 \mathrm{~km}^{2}$. Essa bacia localiza-se geograficamente no Oeste Paulista, em uma região conhecida como Pontal do Paranapanema e envolve centros urbanos como as cidades de Presidente Prudente, Presidente Bernardes, Santo Anastácio, Marabá Paulista e outras cidades da região.

O contexto ambiental da Bacia do rio Santo Anastácio oferece uma unidade geográfica básica de estudo que possibilita avançar na compreensão sobre as relações pretéritas entre o assentamento guarani, seu entorno ambiental e estratégias de subsistência.

Cada local de implantação de um sítio arqueológico se relaciona com seu compartimento geográfico, gerando padrões na apropriação do espaço que podem ser percebidos e, posteriormente, comparados através da leitura das variáveis ambientais dos componentes do meio físico-biótico.

Nessa perspectiva, a demarcação da área do sítio serviu de base para delimitar os fatores ambientais de entorno, tais como: a distância existente entre o sítio e os cursos fluviais mais significativos (rio grande, córregos e afluentes), vegetação, geomorfologia, pedologia e geologia - todos associados à captação de recursos e como topografia favorável a moradia e proteção (Thomaz 2002).

O sítio arqueológico Célia Maria está localizado em área de cultivo de cana de açúcar, em média-baixa vertente, com altitude entre 400 e $404 \mathrm{~m}$, próximo à cabeceira de nascente. $\mathrm{O}$ sítio encontra-se dentro do perímetro da cidade de Marabá Paulista, extremo oeste do Estado de São Paulo. O pequeno córrego que corta a cabeceira de drenagem a leste do sítio - córrego do Itapiranga - é afluente do córrego Areia Dourada, pertencente à Bacia do Rio Santo Anastácio que, por sua vez, deságua no Rio Paraná.

Existe nas proximidades do sítio, a 41,2 m, um antigo percurso de nascente, ao passo que a nascente atual encontra-se a $60 \mathrm{~m}$ da antiga aldeia. Foram contabilizados no compartimento de cabeceira de nascentes, aproximadamente, 15 afloramentos de água que confluem em direção a um canal formador do córrego do Itapiranga.

Seguindo-se as margens do Córrego Itapiranga por cerca de seis quilômetros, encontra-se sua confluência com o Ribeirão Areia Dourada, e dali serão mais oito quilômetros, aproximadamente, até a foz com o Rio Santo Anastácio, e a partir desse ponto até a confluência do Rio Santo Anastácio com o Paraná serão mais 24 quilômetros. Por outro lado, seguindo-se em direção aos topos de interflúvios situados ao sul do sítio, ultrapassando-os em direção ao Rio Paranapanema, este estará a 48 quilômetros de distância do sítio em apreço. 
As distâncias do sítio Célia Maria em relação aos principais corpos fluviais do Pontal do Paranapanema permitem inferir a importância da localização do assentamento em relação aos recursos hídricos disponiveis nessa região.

A caracterização do contexto geomorfológico do sítio Célia Maria foi possível devido às definições de classes de tipologia topomorfológica para sítios arqueológicos localizados na Bacia do Paranapanema paulista, elaborada por Morais (1999). O autor apresenta uma série de "padrões de escolha de compartimentos para o estabelecimento de populações indígenas précoloniais" (Morais 1999: 80) que foram sendo delineadas pela metodológia do ProjPar, a partir da década de 1980.

Se observarmos a paisagem de entorno do sítio Célia Maria veremos que ele está implantado na vertente média-inferior de uma colina ampla, próximo a cabeceira de nascente.

O sítio localizado em compartimento de colina apresenta suas estruturas antropogênicas mais frequentemente recobertas por uma capa de colúvio arenosa pouco espessa. No entanto estas estruturas encontram-se por vezes afloradas devido aos processos erosivos da ação de implementos agrícolas. As referências de nível local foram às nascentes que formam o Córrego do Itapiranga a 60 m de distância, assim como, aos depósitos marginais de argila localizados a $280 \mathrm{~m}$ de distância do sítio.

Apesar de o sítio estar situado quilômetros longe dos rios importantes da região, onde foram mais comuns as instalações de antigas aldeias Guarani, observou-se uma preocupação de ordem locacional, quanto ao seu posicionamento. Observando a paisagem do topo de sua colina teremos um amplo domínio visual de todo entorno de ambientação, em um raio que pode atingir alguns quilômetros de distância.

$\mathrm{O}$ sítio não apresentou, em suas proximidades, fontes litológicas aptas ao lascamento como as cascalheiras, diques clásticos e pavimentos detríticos. Talvez, por essa razão, não tenham sido encontrados no perímetro do sítio nenhum resíduo ou artefato em pedra que evidenciasse o processamento de instrumentos líticos por lascamento, apenas um fragmento de tembetá polido.
No entanto, matérias-primas, aptas à indústria lítica e externas à bacia em apreço foram coletadas em contexto arqueológico como os seixos de arenito silicificado, silexito, quartzo e basalto. É provável que esses seixos procedam da calha fluvial do Alto Paraná ou das cascalheiras do Baixo Paranapanema.

As fontes de argila preta e argila branca encontradas no entorno do sítio foram consideradas adequadas para a fabricação das vasilhas, sem que se deixasse de lado a hipótese do uso de outras fontes de argila mais afastadas.

Os relatos etno-históricos sobre a região do Baixo Paranapanema possibilitam inferir uma segunda importância para as áreas de barreiros (fontes de argila) próximas às margens de córregos e rios:

"Nos barreiros, pontos da margem do rio, onde o barro é salitrado, o ajuntamento da caça em certa hora do dia é coisa extraordinária. Todos os animais aí vêm comer sua ração, desde a anta corpulenta até a pomba esquiva." (Sampaio 1890: 118).

Tratando as paisagens antigas da Bacia do Santo Anastácio e de sua cobertura vegetal primitiva como florestas densas e de mata latifoliada tropical alta (Stein 1999: 107-108), não é difícil imaginar um ambiente repleto de animais corpulentos propícios à atividade da caça. Além das terras adequadas à atividade agrícola e dos terrenos suavizados da bacia, propícios ao assentamento, as nascentes e os barreiros ofereciam elementos vitais para a sobrevivência de um grupo Guarani, naquela paisagem. Os trabalhos de reconhecimento geral da área de entorno do sítio Célia Maria levantaram dados ambientais importantes para a compreensão o cenário da ocupação pretérita.

\section{Os registros arqueológicos}

Os registros arqueológicos apresentados no sítio Célia Maria constituíram-se de fragmentos de cerâmica, fragmento de tembetá, estrutura de combustão e núcleos de solos antropogênicos, produzidos pela sociedade do passado. Abrangem, nesse contexto, assinaturas arqueológicas evidentes e latentes, materializadas pelos artefatos cerâmicos e líticos, assim 
como pelas assinaturas químicas, consolidadas pelos núcleos de solos antropogênicos (Morais 2006).

No sítio arqueológico Célia Maria, a cerâmica constituiu o registro mais significativo. No entanto, seu estado de conservação dificultou a obtenção de dados referentes ao significado funcional dos fragmentos, bem como na identificação dos elementos gráficos pintados.

A análise dos fragmentos cerâmicos privilegiou os aspectos tecnológicos usados na confecção dos vasos, assim como, na sua distribuição espacial em sítio. Esta abordagem permeia uma metodologia de análise que permitiu "caracterizar e oferecer elementos, para discussão e compreensão, da sequência de gestos técnicos realizados para a produção dos artefatos da indústria cerâmica" (Faccio 1998: 132).

Esta análise resume-se no registro, classificação e cruzamento dos atributos tecnomorfológicos e estilísticos da cerâmica. A terminologia arqueológica brasileira, criada por Chmyz (2002), foi suporte na classificação dos artefatos e auxiliou na padronização dos termos empregados nesse registro. A metodologia para análise da cerâmica foi desenvolvida por Faccio (1992) para atender às necessidades da análise cerâmica Guarani da área do ProjPar.

\section{Resultados da análise dos fragmentos cerâmicos}

Foram analisadas um total de 4715 peças, que após análise foram distribuídas por classe de fragmentos ou seção de vaso, conforme mostra a tabela 1 .

O número reduzido de bases apresentadas deve-se ao estado de fragmentação das peças que, muitas vezes, impossibilitou averiguar com precisão essa seção do antigo vaso. Quanto às paredes, elas foram predominantes na classificação dos fragmentos analisados (com 85,64\% dos casos) seguidas dos fragmentos de borda ( $\operatorname{com}$ 9,92\% dos casos).

Após a distribuição por classes de fragmentos, foram identificadas nos mesmos as ocorrências de antiplásticos contidos nos fragmentos cerâmicos.

Para Faccio esse material foi:

"Utilizado para neutralizar a plasticidade da argila, dar condições para boa secagem e queima, aumentar ou diminuir a resistência do choque térmico ou mecânico, diminuir ou aumentar a porosidade ou permeabilidade." (Faccio 1998: 134).

A frequência do antiplástico mineral foi de $29,20 \%$, enquanto que a do mineral associado

\begin{tabular}{|c|c|c|}
\hline Classe do Fragmento & $\begin{array}{l}\text { Número de } \\
\text { ocorrências }\end{array}$ & Frequência \\
\hline Parede & 4038 & $85,64 \%$ \\
\hline Borda & 468 & $9,92 \%$ \\
\hline Base & 13 & $0,27 \%$ \\
\hline Parede angular & 159 & $3,37 \%$ \\
\hline Parede e base & 4 & $0,08 \%$ \\
\hline Bolota de argila & 6 & $0,12 \%$ \\
\hline Borda com suporte para tampa & 6 & $0,12 \%$ \\
\hline Polidor de sulco & 2 & $0,04 \%$ \\
\hline Borda com parede angular & 18 & $0,38 \%$ \\
\hline Base, parede e borda & 1 & $0,02 \%$ \\
\hline TOTAL & 4.715 & $100 \%$ \\
\hline
\end{tabular}

Tabela 1: Distribuição dos fragmentos cerâmicos do sítio arqueológico Célia Maria pelas classes de análise. 
ao de caco moído foi de 70,79\%. Esses números indicam que, além da reciclagem dos vasos cerâmicos, a cerâmica moída era muito popular na confecção desses recipientes sendo, no caso do sítio Célia Maria, essencial para obter uma massa de argila adequada no manuseio.

Por meio de uma análise mais apurada, o antiplástico mineral foi isolado medindose a espessura dos maiores grãos de quartzo encontrados na pasta de todos os fragmentos de cerâmica analisados. A espessura fina foi predominante, se apresentando em 99,05\% dos casos. É possível perceber que a retirada de grãos minerais maiores que $0,2 \mathrm{~cm}$ foi intencional, pois a pasta apresenta granulometria padrão e uniforme.

O mesmo teste descrito acima foi aplicado ao antiplástico caco moído, associando-o à sua categoria de variação granulométrica. Verificou-se que a maior parte dos cacos de cerâmica foram bem triturados e se apresentaram, em $79,74 \%$ dos casos, na categoria finos, tendo a espessura do seu maior grão variando de 0,1 a $0,2 \mathrm{~cm}$ (tabela 2). Essa breve avaliação mostra que o antiplástico preferido para a confecção dos vasos foi o caco moído, bem triturado, de granulação fina que, misturado à argila, formou a pasta predominante no sítio Célia Maria.

\begin{tabular}{lcc}
\hline Categorias & $\begin{array}{l}\text { Número de } \\
\text { ocorrências }\end{array}$ & $\begin{array}{l}\text { Frequên- } \\
\text { cia }\end{array}$ \\
\hline De 0,1 a 2 cm (fina) & 2.662 & $79,74 \%$ \\
De 0,21 a 0,4 cm (média) & 648 & $19,41 \%$ \\
De 0,41 a 0,9 cm (grossa) & 28 & $0,83 \%$ \\
\hline TOTAL & 3.338 & $100 \%$ \\
\hline
\end{tabular}

Tabela 2: Variações granulométricas do antiplástico caco moído dos fragmentos cerâmicos do sítio arqueológico Célia Maria.

A tabela 3 apresenta a relação entre a espessura da parede e o tipo de pasta. A pasta foi classificada em três tipos, relacionando-se a quantidade de argila com a de antiplástico: 1- plástica, existiu o predomínio da argila sobre o antiplástico; 2 -intermediária apresentou certa equivalência entre o antiplástico, geralmente o caco moído, e a argila e 3- dura, houve o predomínio do antiplástico em relação à argila. A análise da relação entre a quantidade de antiplástico e argila foi feita a partir da quebra de parte dos fragmentos cerâmicos em pedaços de aproximadamente $1 \mathrm{~cm}$, sendo feita, por inspeção visual, a avaliação espacial da presença de argila em relação ao antiplástico.

$\mathrm{Na}$ categoria parede fina, com espessura dos cacos cerâmicos variando de 0,15 a 0,8 cm, a pasta plástica esteve presente em 918 casos ou $19,46 \%$, sendo predominante nessa categoria. A pasta intermediária apresentou-se em 320 casos ou $6,78 \%$ e a pasta dura, em apenas, 70 ocorrências ou $1,48 \%$.

$\mathrm{Na}$ categoria parede média, com variáveis de 0,81 a $1,5 \mathrm{~cm}$ de espessura, a pasta intermediária apresentou-se em 1.216 casos ou 25,79\%, aproximando-se numericamente da porcentagem com pasta plástica, com 1.532 casos ou $32,49 \%$. Nota-se, também, que a pasta dura subiu de produção, apresentando nessa categoria 154 casos ou 3,2\%. Essa observação nos indica que conforme a espessura da parede aumenta, ocorre maior acréscimo de antiplástico na massa de argila.

Na última categoria, parede grossa com variantes de 1,51 a $3,5 \mathrm{~cm}$, a predominância foi da pasta de tipo intermediário, com 289 casos ou $6,1 \%$. A pasta grossa apresentou 54 casos ou $1,14 \%$ e, em relação ao número dos outros tipos de pasta dentro dessa categoria, apresentou crescimento percentual. A pasta plástica declinou em porcentagem e esteve presente em 162 casos.

A parede grossa foi confeccionada, predominantemente, com o antiplástico caco moído, evidenciando a tendência dos artesãos em acrescentar esse "tempero" às paredes médias e grossas, enquanto nas paredes finas predominou o acréscimo do antiplástico mineral, assumindo-se que tenha sido acrescido intencionalmente.

Essa classificação teve por objetivo registrar as tendências de escolha dos artesãos na produção da massa de argila e sua relação com a espessura das paredes. Observou-se também que as paredes finas podiam sustentar-se sem o acréscimo de quantidades significativas de caco moído, no entanto, a habilidade do artesão em confeccionar paredes de espessura mínima com 


\begin{tabular}{|c|c|c|}
\hline Categorias & $\begin{array}{l}\text { Número de } \\
\text { ocorrências }\end{array}$ & Frequência \\
\hline \multicolumn{3}{|l|}{ PAREDE FINA } \\
\hline De 0,15 a $0,8 \mathrm{~cm}$ com pasta plástica & 918 & $19,46 \%$ \\
\hline De 0,15 a $0,8 \mathrm{~cm}$ com pasta intermediária & 320 & $6,78 \%$ \\
\hline De 0,15 a $0,8 \mathrm{~cm}$ com pasta dura & 70 & $1,48 \%$ \\
\hline Total Parede Fina & 1.308 & $27,72 \%$ \\
\hline \multicolumn{3}{|l|}{ PAREDE MÉDIA } \\
\hline De 0,81 a $1,5 \mathrm{~cm}$ com pasta plástica & 1532 & $32,49 \%$ \\
\hline De 0,81 a $1,5 \mathrm{~cm}$ com pasta intermediária & 1216 & $25,79 \%$ \\
\hline De 0,81 a $1,5 \mathrm{~cm}$ com pasta dura & 154 & $3,26 \%$ \\
\hline Total Parede Média & 2902 & $61,54 \%$ \\
\hline \multicolumn{3}{|l|}{ PAREDE GROSSA } \\
\hline De 1,51 a $3,5 \mathrm{~cm}$ com pasta plástica & 162 & $3,43 \%$ \\
\hline De 1,51 a $3,5 \mathrm{~cm}$ com pasta intermediária & 289 & $6,12 \%$ \\
\hline De 1,51 a $3,5 \mathrm{~cm}$ com pasta dura & 54 & $1,14 \%$ \\
\hline \multirow[t]{2}{*}{ Total Parede Grossa } & 505 & $10,69 \%$ \\
\hline & 4.715 & $100 \%$ \\
\hline
\end{tabular}

Tabela 3: Relação entre espessura da parede e tipo de pasta dos fragmentos cerâmicos do sítio Célia Maria.

uma argila tão plástica constitui sinal de muita destreza. Essa destreza observada nas paredes finas mostrou-se quase impossivel de ser mantida na confecção de vasilhames de paredes mais grossas, assim, as paredes de maior espessura necessitaram de maior quantidade de caco moído para que se mantivessem no formato desejádo.

Quanto à eficiência no uso do fogo e no manuseio dos vasos cerâmicos durante sua queima, registra-se que os grupos Guarani não usavam fornos para a queima de seus vasos cerâmicos, e que esse processo era feito em uma fogueira com certo controle térmico por parte dos artesãos. No entanto, esse controle não poderia ser uniforme em todas as partes do vaso. Assim, um único vaso pode ter diversos tipos de queima, ora completa ou parcialmente completa de um lado, ora incompleta de outro.

Nas últimas etapas de acabamento da pasta de argila, pode-se acrescentar ou não o banho por barbotina. O banho de barbotina "é um revestimento superficial de argila mais refinada, aplicado a cerâmica antes da queima" (Brochado e La Salvia 1989: 17). Sua função dentro do projeto de confecção das vasilhas pode estar relacionada a um elemento corre- 
tivo, eliminando rugosidades persistentes às atividades de alisamento e fechando as lacunas entre os roletes.

Nosso objetivo nessa etapa foi averiguar o número de ocorrências da barbotina nas duas faces dos fragmentos. Observou-se que foi comum a inserção da barbotina nas duas faces dos recipientes cerâmicos com 38,62\% dos casos analisados. No entanto, a não inserção da barbotina nas duas faces também atingiu um alto nível de porcentagem, com 35,90\% dos casos. Parte dessa observação pode resultar da má conservação dos fragmentos cerâmicos, principalmente de sua superfície, que ocasionou, em vários casos, o registro do desprendimento da barbotina em relação à pasta produtiva.

Na tabela 4 são apresentados os resultados encontrados para o tratamento de superfície de ambos os lados dos fragmentos cerâmicos. A análise dos dados demonstra que 79,59\% dos fragmentos foram alisados interna e externamente. O engobo esteve presente em 11,85\% das peças, enquanto a pintura esteve presente em 8,14\% dos casos. Dos 4.715 fragmentos cerâmicos analisados, 926 deles apresentaram engobo, pintura ou a associação de ambos.
A rara presença da decoração plástica foi registrada em 39 fragmentos. A maior parte das peças com decoração plástica apresentou incisão com representações de motivos associados à pintura ou incisões isoladas paralelas aos lábios das bordas.

Após a análise do tratamento de superfície, isolamos o tipo de tratamento pintado e/ou com a presença de engobo nas superfícies interna e externa dos fragmentos cerâmicos coletados no sítio Célia Maria. A grande maioria dos fragmentos dos tipos com engobo, com pintura, ou com engobo e pintura apresentaram essa característica em sua parte interna. Partindo da premissa de que a pintura é uma manifestação artística e religiosa, usada sobretudo em atividades sociais e ritualísticas, reforçamos a tese de que ela deveria estar sempre à mostra para o observador, em campo visível, dentro do recipiente. Assim, pinturas e tratamentos decorativos, localizados na parte interna da cerâmica, poderiam significar vasilhas abertas ou muito abertas (Soares 2004).

Em termos quantitativos, 687 fragmentos de cerâmica apresentaram algum tipo de tratamento decorativo em sua superfície interna. É

\begin{tabular}{|c|c|c|}
\hline Tratamento & $\begin{array}{l}\text { Número de } \\
\text { ocorrências }\end{array}$ & Frequência \\
\hline Alisado interno - externo & 3753 & $79,59 \%$ \\
\hline Alisado interno - engobo externo & 121 & $2,56 \%$ \\
\hline Engobo interno - elisado externo & 328 & $6,95 \%$ \\
\hline Engobo interno - externo & 87 & $1,84 \%$ \\
\hline Engobo interno - pintura externa & 22 & $0,46 \%$ \\
\hline Pintura interna - engobo externo & 24 & $0,50 \%$ \\
\hline Alisado interno - pintura externa & 119 & $2,52 \%$ \\
\hline Pintura interna - alisado externo & 204 & $4,32 \%$ \\
\hline Pintura interna - externa & 18 & $0,38 \%$ \\
\hline Alisado interno - decoração plástica externa & 36 & $0,76 \%$ \\
\hline Decoração plástica externa - alisado interno & 3 & $0,06 \%$ \\
\hline TOTAI & 4.715 & $100 \%$ \\
\hline
\end{tabular}

Tabela 4: Tratamento de superfície do lado interno e do lado externo dos fragmentos cerâmicos do sítio arqueológico Célia Maria. 
provável que tais fragmentos sejam os resquícios de antigos ñaembé ou cambuchi caguâba, que se somavam neste antigo espaço habitacional. Mesmo que não haja forma para eles, a própria pintura pode sugerir suas funções, em vista da inexistência de reconstituições gráficas que remetessem à vasilha cambuchi, estando a pintura particularmente reservada nesse sítio a pratos e tigelas de usos especiais, provavelmente servindo a propósitos ritualísticos ou especiais.

Por outro lado, 395 fragmentos de cerâmica apresentaram tratamento decorativo em sua face externa. Estes remeteriam a formas de tigelas com bordas mais convexas, ou até mesmo carenadas, nas quais a face externa fosse privilegiada na observação. Cabe lembrar que, dentro do número apresentado, 160 fragmentos mostraram tratamento decorativo em ambas as faces, talvez implicando formas mais equilibradas, quanto ao campo visual, que pudessem ser visualizadas em suas duas faces ao mesmo tempo.

$\mathrm{Na}$ tabela 5, podem-se verificar as classes de ocorrência das 238 bordas classificadas, outras 230 bordas não foram quantificadas, porque se apresentaram muito fragmentadas e/ou impossíveis de serem classificadas.

Entre as 238 bordas classificadas, apenas 42 apresentaram condições seguras para sua reconstituição gráfica, as quais foram agrupadas em conjuntos funcionais estabelecidos pela sua forma. Na categoria panelas pequenas, foi reconstituída a forma de sete vasos e na categoria panelas médias, a forma de onze vasos. $\mathrm{Na}$ categoria caçarolas médias, foram reconstituídas duas formas de vasilhas. Na categoria tigelas abertas foram reconstituídas cinco formas de vasilhas, na categoria tigelas infletidas duas formas, na categoria pratos cinco formas, na categoria tigelas carenadas quatro formas e na categoria tigelas com borda vertical seis formas.

As panelas foram usadas para cozinhar os alimentos, aquecê-los ao fogo e estão sempre relacionadas à preparação por fervura (Brochado e Monticelli 1994; La Salvia e Brochado 1989). Possuem bordas verticais ou inclinadas para fora, formando paredes infletidas. Nessa categoria, foram consideradas 18 bordas, todas lisas, sem a presença de tratamento de superfície plástico. As bordas das panelas possuem dimensões que variam de 12 a $28 \mathrm{~cm}$ de diâmetro da boca.

Nessa pesquisa, foi considerada pertinente uma divisão do conjunto de vasilhas, segundo seu tamanho e possivel função, como o procedimento adotado por Brochado e Monticelli (1994), dividindo-as em: pequenas, aquelas com diâmetro de boca entre 12 e $16 \mathrm{~cm}$ e médias com diâmetro de boca entre 18 e $30 \mathrm{~cm}$. As

\begin{tabular}{lcc}
\hline \multicolumn{1}{c}{ Classe de bordas } & $\begin{array}{r}\text { Número de } \\
\text { ocorrências }\end{array}$ & Frequência \\
\hline Borda direta & 81 & $34,03 \%$ \\
Borda direta inclinada interna & 6 & $2,52 \%$ \\
Borda direta inclinada externa & 65 & $27,31 \%$ \\
Borda extrovertida inclinada interna & 13 & $5,46 \%$ \\
Borda extrovertida inclinada externa & 38 & $15,96 \%$ \\
Borda extrovertida vertical & 9 & $3,78 \%$ \\
Borda introvertida interna & 14 & $5,88 \%$ \\
Borda carenada & 11 & $4,62 \%$ \\
Borda cambada & 1 & $0,42 \%$ \\
\hline \multicolumn{1}{c}{ TOTAL } & 238 & $100 \%$ \\
\hline
\end{tabular}

Tabela 5: Ocorrência das diferentes classes de borda nos fragmentos cerâmicos do sítio arqueológico Célia Maria 
panelas grandes com dimensões maiores que $32 \mathrm{~cm}$ não tiveram representação no contexto do sítio Célia Maria.

Entre os fragmentos de bordas com diâmetro de boca pequeno foram quantificados dois com $12 \mathrm{~cm}$ de diâmetro, um com $14 \mathrm{~cm}$ de diâmetro e quatro com $16 \mathrm{~cm}$ de diâmetro. Entre os fragmentos de bordas com diâmetro de boca médio foram quantificados cinco com 18 $\mathrm{cm}$ de diâmetro, um com $20 \mathrm{~cm}$ de diâmetro, um com $22 \mathrm{~cm}$ de diâmetro, dois com $24 \mathrm{~cm}$ de diâmetro e dois com $28 \mathrm{~cm}$ de diâmetro.

Por meio dos dados quantitativos, podemos observar que a maior parte dos fragmentos de bordas de antigas panelas varia de $16 \mathrm{~cm}$ a $18 \mathrm{~cm}$ de diâmetro de boca, faixa de medida que ocorre entre as panelas pequenas e as panelas médias. Como já exposto anteriormente, acreditamos que as vasilhas, no caso contextual as panelas, de pequenas e médias dimensões podem ter sido utilizadas por grupo ou grupos de famílias nucleares de número restrito de pessoas.

As caçarolas ou ñaetá são vasilhas representadas por uma "forma aproximadamente tronco-cônica, com borda direta, contínua com a parede, aproximadamente vertical ou inclinada para fora e base aplainada ou levemente arredondada" (Brochado e Monticelli 1994: 112). Assim como as panelas, elas estão associadas ao preparo de alimentos por fervura sobre o fogo. Nessa categoria, foram consideradas duas bordas, todas lisas, sem a presença de tratamento de superfície plástico. As bordas das caçarolas possuem dimensões de $34 \mathrm{~cm}$ de diâmetro da boca, para um caso e $40 \mathrm{~cm}$ de diâmetro da boca para o outro.

Na dimensão do diâmetro de suas bocas, ambos os fragmentos de bordas de caçarolas foram classificados como medianos, não existindo representação no sítio Célia Maria para o tipo grande, ou seja, aqueles com diâmetro maior que $50 \mathrm{~cm}$. As caçarolas reforçam que o tamanho dos recipientes cerâmicos até agora reconstituídos, para a área do sítio arqueológico Célia Maria, sempre atingiram a categoria pequena e média e nunca chegaram à categoria grande.

Com vinte reconstituições de bordas para vasilhas de cozinhar, não foi possível entender o conjunto de recipientes que formaram o kit doméstico de preparo do alimento nessa antiga ocupação Guarani. Fica, no entanto, em evidência, que na questão do preparo de alimentos não houve reconstituições de bordas que atestassem a presença de um número grande de pessoas nesse assentamento, pelo fato de todas as vasilhas estarem classificadas como pequenas e médias. Acreditamos, a partir dos dados apresentados até agora, que o número de pessoas que habitaram esse antigo assentamento era pequeno, possivelmente, pertenciam a uma família extensa, formada por poucas famílias nucleares.

O prato de comer foi nomeado por Montoya como tembiiru ou ñaembé. Pode ser identificado por meio de suas formas muito abertas, "com a borda convexa, contínua com as paredes, aproximadamente vertical ou inclinada para fora" (Brochado e Monticelli 1994: 115). Assim, as bordas reconstituídas, possuindo as características sugeridas pelos autores citados e que apresentaram uma tendência a formas mais abertas, foram consideradas, neste trabalho como pratos. Nessa categoria foi analisada a reconstituição de cinco bordas diretas inclinadas para fora ou convexas, com tratamento de superfície liso ou pintado interno ou externo. $\mathrm{O}$ diâmetro das bordas de prato variou de $16 \mathrm{~cm}$ a $36 \mathrm{~cm}$.

As dimensões do diâmetro da boca das bordas nos possibilitaram classificá-las em pequena, média e grande. Apenas um fragmento de borda com diâmetro de boca pequeno foi reconstituído e seu diâmetro foi de $16 \mathrm{~cm}$. Igualmente, apenas um fragmento de borda com diâmetro de boca médio foi reconstituído apresentando diâmetro de $18 \mathrm{~cm}$. Entre os fragmentos de bordas com diâmetro de boca grande foram reconstituídos três fragmentos de bordas, um com $34 \mathrm{~cm}$ de diâmetro e dois com $36 \mathrm{~cm}$ de diâmetro. A análise dos fragmentos de borda de pratos grandes sugere que algumas refeições poderiam ter sido coletivas, "uma vez que os pratos médios e grandes serviram a refeições comunais" (Soares 2004: 74).

No entanto, esses dados não são suficientes para alegarmos que no sítio Célia Maria ocorreram atividades sociais de grande porte, pois foi rara a presença de recipientes cerâmicos reconstituídos de dimensões grandes, principalmente 
aqueles destinados ao preparo dos alimentos como as panelas e as caçarolas.

Nas tigelas de beber ou cambuchi caguaba, consideramos as reconstituições de bordas que remetessem a formas semelhantes às tigelas com bordas introvertidas, carenadas, diretas verticais ou inclinadas externas. Semelhante ao trabalho de Soares (2004) as tigelas que apresentaram ângulo formando carena devem ter constituído vasilhas restringidas no passado, provavelmente com base mais aplanada e pouco profunda, se comparadas às vasilhas de contorno simples, como as formadas por bordas introvertidas e diretas. No entanto, Soares afirma que essas tigelas possuíam pintura externa, fato não corroborado no sítio Célia Maria. Dois exemplares desse tipo de vasilha possuíram pintura vermelha sobre engobo branco em sua face interna.

As tigelas de beber carenadas foram todas classificadas como médias, variando o diâmetro da boca entre $22 \mathrm{~cm}$ e $28 \mathrm{~cm}$. As tigelas de beber com bordas diretas levemente inclinadas para fora apresentaram diâmetro de boca pequeno em três casos e diâmetro de boca médio em dois casos. As tigelas de beber com bordas diretas verticais variaram o diâmetro de suas bocas entre $18 \mathrm{~cm}$ e $26 \mathrm{~cm}$. Ressaltamos que em dois casos o diâmetro da boca apresentou $28 \mathrm{~cm}$ e $34 \mathrm{~cm}$, dimensões que ultrapassam o limite máximo estabelecido para tigelas medianas por Brochado e Monticelli (1994: 116) e que consideraremos essas duas tigelas que extrapolam tais dimensões como grandes. As tigelas de beber com bordas introvertidas apresentaram diâmetro de boca pequeno, com um exemplar de $14 \mathrm{~cm}$, e diâmetro de boca médio, com um exemplar de $22 \mathrm{~cm}$.

Em números gerais, as tigelas para beber, de tamanho pequeno, representaram $23,52 \%$ dos casos, as de tamanho médio representaram $58,82 \%$ dos casos e as de tamanho grande $17,64 \%$ dos casos. Considerando o uso destas tigelas para o consumo de alimentos e bebidas e que a maioria delas possui o tamanho médio, seguido pelas pequenas e depois pelas grandes, colocamos a hipótese do uso desses recipientes individualmente ou por pequenos grupos, não justificando atividades coletivas nas quais grandes recipientes fossem usados para beber coletivamente.

Os tratamentos de superfície com decoração por pintura nos sítios regionais estavam, provavelmente, associados ao banho de barbotina, oferecendo uma camada lisa e sem fissura acompanhada ou não por engobo, produzindo um revestimento pigmentado à superfície cerâmica, seguido pelo desenho ou "ação de agregar pigmento colorido na superfície cerâmica, através de um objeto intermediário, produzindo elementos retilíneos e curvilíneos que se associam de diversas maneiras" (Scatamacchia 2004: 301).

Os elementos gráficos da pintura Guarani geralmente são constituídos por expressão decorativa que vão formando os motivos básicos do desenho. Nesse contexto, as linhas onduladas e retas, pontos, triângulos, traços e faixas irão compor todo o sistema de representação visual Guarani. A decoração Guarani apresentase por zonas, sendo uma secundária, formada por elementos mais simples, seguida de uma principal, formada por desenhos geométricos que se repetem e preenchem parte da vasilha respeitando a sua forma.

Nos trabalhos sobre sítios do Vale do Rio Paranapanema e Alto Paraná, observamos o uso de um ou mais motivos mínimos nas vasilhas Guarani. Faccio (2011) comenta que a quantidade de motivos mínimos e sua forma variaram de sítio para sítio e que a opção por trabalhar com esse tipo de metodologia de análise se baseia na suposição de que esses desenhos elementares tenham significados para os índios Guarani e, se bem conhecidos, poderão aprofundar sua interpretação com base nos registros etnográficos.

No trabalho de análise cerâmica do sítio Célia Maria, identificamos poucos motivos mínimos. As linhas curvas, formando feixes preenchidos ou não por pontos, foram os motivos mínimos mais corriqueiros para os fragmentos pintados internamente no sítio Célia Maria (fig. 1: números de 1 a 5). Notou-se a presença de motivos mínimos na face externa dos fragmentos de linhas retilíneas concêntricas compondo o motivo em grega, sempre pintado na cor vermelha (fig. 1: números 2, 8, 9 e 10). Outras situações apresentaram motivos complexos não visualizados em sua totalidade, e que não estão 
representados na figura 1 . A variabilidade de formas e padrão de motivos em cerâmica pôde ser apreciada nos motivos mínimos levantados, o que formou um pequeno quadro referencial local, mostrando as especificidades dos desenhos desse sítio.
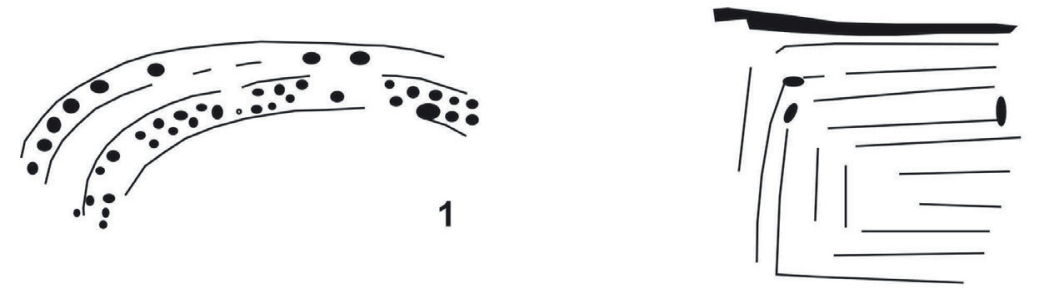

2
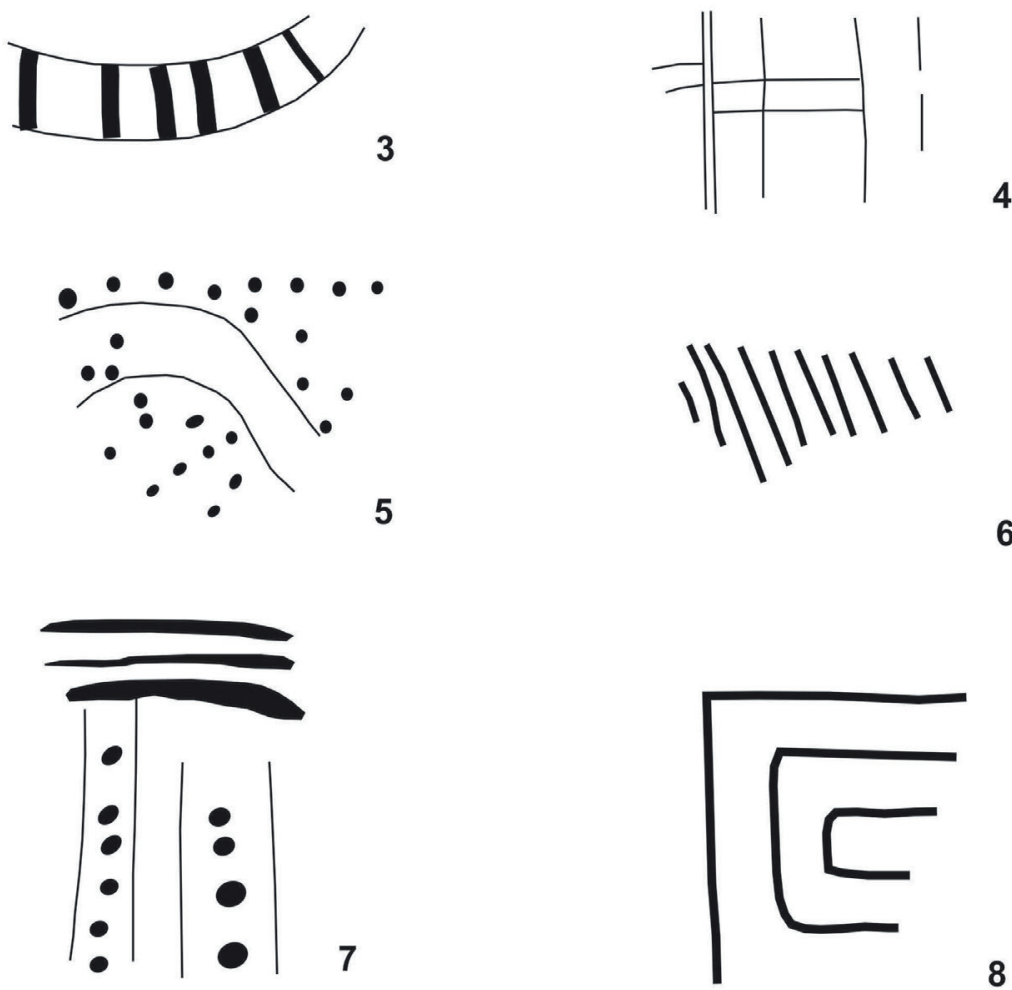

8
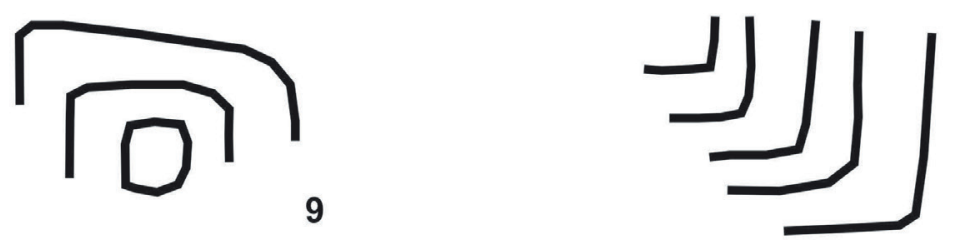

Fig.1: Motivos mínimos da cerâmica Guarani do sítio arqueológico Célia Maria 


\section{Considerações finais}

O sítio Célia Maria, localizado no extremo oeste do Estado de São Paulo, na Bacia do Rio Santo Anastácio, encontra-se próximo do topo de interflúvios que separam as Bacias do Paraná e Paranapanema. A datação de 450 anos antes do presente aproxima-o temporalmente dos sítios localizados no Alto Paraná, MS e do Baixo Paranapanema, mais especificamente no Município de Iepê, SP.

Acreditamos numa possível expansão Guarani que levou à ocupação de territórios nos grandes vales fluviais e na região de interfluvios próximos dos afluentes dos grandes rios. A análise feita entre as grandes aldeias do Paraná e Paranapanema com o sítio Célia Maria permitiu afirmar que o sistema social/cultural Guarani definiria hierarquias de ocupação das áreas, partindo das zonas ecológicas mais favoráveis as menos favoráveis.

O sítio arqueológico Célia Maria apresentou 42 reconstituições gráficas de formas de vasilhas, a partir de fragmentos de bordas, mostrando que a maior parte das vasilhas possuía dimensões pequenas e médias, sendo utilizadas, possivelmente, por um número reduzido de pessoas. A cambuchi utilizada como recipiente de armazenamento de líquidos, assim como na fermentação das bebidas alcoólicas, muito apreciadas nas festividades Guarani, está ausente no sítio em apreço, pelo menos, no que se refere às reconstituições gráficas das formas, a partir dos fragmentos de bordas. A "ausência" desse tipo de recipiente pode representar, igualmente, a carência ou, até mesmo, a inexistência de grandes festas, como, possivelmente, acontecia nas grandes aldeias próximas ao Rio Paranapanema.
A pequena dimensão dos recipientes parece estar associada a pouca variabilidade do tratamento de superfície de sua cerâmica. A pintura associada ao engobo esteve presente em 926 fragmentos cerâmicos, de um total de 4.715 . A rara presença do tratamento plástico foi contabilizada em apenas 39 fragmentos incisos. O corrugado e outros tratamentos de superfície plástica inexistiram nas amostras analisadas.

Sem ser registrada nas análises de fragmentos cerâmicos do sítio Célia Maria, a produção e o uso de grandes recipientes cerâmicos como as cambuchi e as grandes yapepó, presume-se que a tralha doméstica do grupo Guarani que habitou o sítio Célia Maria era formada por pequenas panelas, pratos (ñaembé), e uma diversidade de tigelas de usos especiais - as que apresentaram pintura - e de uso cotidiano. Como já comentado, essa realidade da cultura material poderia expressar o baixo prestígio dessa aldeia em relação às situadas em áreas ecológicas mais favoráveis.

Finalmente, reiteramos que as áreas densamente ocupadas dos terraços e várzeas do Alto Paraná ou Baixo Paranapanema teriam sido a origem do deslocamento Guarani para a região dos pequenos afluentes desses dois grandes rios, como foi o caso da cabeceira de nascente, onde se encontra o sítio Célia Maria. No entanto, os detalhes do desmembramento das aldeias e os possíveis limites dos tekoas Guarani só podem ser contemplados por meio das fontes etno-históricas e etnográficas. Os dados arqueológicos ainda não permitem inferir como se deu a expansão Guarani em nosso cenário de estudo, e o que teria levado pequenos grupos a buscar áreas distantes daquelas de melhor representação ecológica e estratégica. 
PEREIRA, D.L.T.; FACCIO, N.B. Guarani Archaeology in Santo Anastácio Basin, State of São Paulo: study of the variability in ceramics from Célia Maria Site. R.. Museu Arq. Etn., 24: 77-90.

\begin{abstract}
The research conducted in the area of Célia Maria Archaeological Site, situated in the region of Santo Anastácio Basin (affluent of Paraná Basin), São Paulo State, demonstrated a pre-colonial Guarani occupation. Thermoluminescence showed the ceramics are dated back around to 450 to 460 years. This study brings data concerning the pottery identified in the area of Célia Maria Site. Through the use of techno-typological analysis of ceramics, it was not only shown the probable sequence of gestures used to produce the artifacts, but the shape of the vessels was also graphically reconstituted, from pieces of edges. The spatial data of the attributes of ceramics from Célia Maria Site were compared to other available researches, which examined the presence of Guarani people in both Paraná and Paranapanema Basins.
\end{abstract}

Keywords: Guarani Archaeology; ceramic analysis; Santo Anastácio Basin.

\title{
Referências bibliográficas
}

Brochado, J.P.; La Salvia, F. 1989. Cerâmica Guarani. Porto Alegre: Posenato Arte \& Cultura.

Brochado, J. P; Monticelli, G. 1994. Regras práticas na reconstrução gráfica das vasilhas de cerâmica Guarani por comparação com vasilhas inteiras. Estudos Ibero - Americanos 20( 2): 107-118.

Chmyz, I. 2002. A Tradição Tupiguarani no Litoral do Estado do Paraná. Curitiba: Círculo de Estudos Bandeirantes.

Faccio, N.B. 1992. Estudo do Sítio Arqueológico Alvim no Contexto do Projeto Paranapanema. Dissertação de mestrado. São Paulo: Faculdade de Filosofia Letras e Ciências Humanas, USP.

Faccio, N.B. 1998. Arqueologia dos Cenários das Ocupações Horticultoras da Capivara, Baixo Paranapanema - SP. Tese de doutorado. São Paulo: Museu de Arqueologia e Etnologia, USP.
Faccio, N.B. 2010. Relatório de Resgate do Sítio Arqueológico Célia Maria. FCT/ UNESP.

Milheira, R. 2010. Arqueologia Guarani no Litoral Sul-Catarinense: história e território. Tese de doutorado. São Paulo: Museu de Arqueologia e Etnologia, USP.

Morais, J.L. 1999 Perspectivas Geoambientais da Arqueologia do Paranapanema Paulista. Tese de Livre-Docência. São Paulo: Museu de Arqueologia e Etnologia, USP.

Morais, J.L. 2006. Reflexões acerca da Arqueologia Preventiva. In Mori, V.H.; Souza, M.C.; Bastos, R.L.; Gallo, H. (Org.). Patrimônio: Atualizando o Debate. São Paulo: CONAP, 191-220.

Sampaio, T. 1890. Considerações Geographicas e Econômicas sobre o Valle do Rio Paranapanema. Boletim da Comissão Geographica e 
Geológica do Estado de São Paulo 4. São Paulo: Typographia King.

Scatamacchia, M.C.M. 2004. Proposta de terminologia para descrição e classificação da cerâmica arqueológica dos grupos pertencentes à família linguística Tupi-guarani. Revista do Museu de Arqueologia e Etnologia 14: 291-307.

Soares, A. 1997. Guarani: organização social e arqueologia. Porto Alegre: EDIPUCRS.

Soares, A. 2004. Contribuição à Arqueologia Guarani: o estudo do Sítio Ropke. Tese de dou- torado. São Paulo: Museu de Arqueologia e Etnologia, USP.

Stein, D.P. 2003. Avaliação da degradação do meio físico. Bacia do rio Santo Anastácio, Oeste Paulista. Rio Claro. Tese de doutorado. São Paulo: Instituto de Geociências e Ciências Exatas, UNESP.

Thomaz, R.C.C. 2002. O uso de Sig na predição da localização de sítios arqueológicos: um estudo de caso na bacia do Paraná Superior. Tese de doutorado: Museu de Arqueologia e Etnologia, USP. 